\title{
Molecular characterization of a complex small supernumerary marker chromosome derived from chromosome 18p: an addition to the literature
}

\author{
Eleonora Marchina ${ }^{1 *} \mathbb{D}$, Michela Forti $^{1}$, Mariella Tonelli', Stefania Maccarini ${ }^{1}$, Francesca Malvestiti ${ }^{4}$,
} Chiara Piantoni², Elena Filippini², Elisa Fazzi ${ }^{2}$ and Giuseppe Borsani ${ }^{3}$

\begin{abstract}
Background: Small supernumerary marker chromosomes (SSMC) are a heterogeneous group of structurally abnormal chromosomes, with an incidence of 0,044\% in newborns that increases up to almost 7 times in developmentally retarded patients. SSMC from all 24 chromosome have been described, most of them originate from the group of the acrocentric, with around half deriving from the chromosome 15. Non-acrocentric sSMC are less common and, in the 30 percent of the cases, are associated with phenotypic effect. Complex sSMC consist of chromosomal material derived from more than one chromosome. Genotype-phenotype correlations in patients with sSMC are difficult to assess. Clinical features depend on factors such as its size, genetic content, the involvement of imprinted genes which may be influenced by uniparental disomy and the level of mosaicism. Trisomy of the short arm of chromosome 18 (18p) is an infrequent finding and does not appear to be associated with a specific syndrome. However, mild intellectual disability with or without other anomalies is reported in almost one-third of the patients.
\end{abstract}

Case presentation: Here we present clinical and molecular characterization of a new case of de novo complex sSMC consisting of the entire short arm of chromosome 18p associated with a centromere of either chromosome 13 or 21, evidenced in a 5-year-old boy during diagnostic workup for moderate intellectual disability and dysmorphisms. To date, only seven cases of isolated trisomy 18p due to a sSMC have been reported, three of which have been characterized by array CGH. In two of them the breakpoints and the size of the duplication have been described. In the manuscript we also reviewed cases reported in the DECIPHER database carrying similar duplication and also considered smaller duplications within the region of interest, in order to evaluate the presence of critical regions implicated in the pathological phenotype.

Conclusions: Our case provides additional information about phenotypic effects of pure trisomy $18 p$, confirms chromosomal microarray analysis as gold standard to characterize complex SSMC, and supplies additional elements for genetic counselling.

Keywords: Trisomy 18p, sSMC, a-CGH, Intellectual disability, Dysmorphisms

*Correspondence: eleonora.marchina@unibs.it

1 Laboratory of Cytogenetics and Molecular Genetics, Department of Molecular and Translational Medicine, University of Brescia, Brescia, Italy Full list of author information is available at the end of the article

\section{Background}

Small supernumerary marker chromosomes (sSMC) are a heterogeneous group of structurally abnormal chromosomes, with an incidence of $0.044 \%$ in newborns that increases up to almost 7 times in developmentally

(c) The Author(s) 2021. Open Access This article is licensed under a Creative Commons Attribution 4.0 International License, which permits use, sharing, adaptation, distribution and reproduction in any medium or format, as long as you give appropriate credit to the original author(s) and the source, provide a link to the Creative Commons licence, and indicate if changes were made. The images or other third party material in this article are included in the article's Creative Commons licence, unless indicated otherwise in a credit line to the material. If material is not included in the article's Creative Commons licence and your intended use is not permitted by statutory regulation or exceeds the permitted use, you will need to obtain permission directly from the copyright holder. To view a copy of this licence, visit http://creativecommons.org/licenses/by/4.0/. The Creative Commons Public Domain Dedication waiver (http://creativecommons.org/ publicdomain/zero/1.0/) applies to the data made available in this article, unless otherwise stated in a credit line to the data. 
retarded patients [1]. sSMC derived from all 24 chromosome have been described, the majority of them derive from the group of the acrocentric, with around half originating from chromosome 15 [2,3]. About 30 percent of all sSMC are parentally inherited [4]. Non-acrocentric sSMC are less common and, in 30 percent of the cases, are associated with phenotypic effects [5]. Complex sSMC consist of chromosomal material derived from more than one chromosome.

Genotype-phenotype correlation for sSMCs is a challenging because clinical features depend on their size, the genetic content, the involvement of imprinted genes which may be influenced by uniparental disomy (UPD) and the level of mosaicism [6].

Trisomy of the short arm of chromosome 18 (18p) is an infrequent finding and does not appear to be associated with a specific syndrome. However, mild intellectual disability with or without other anomalies is reported in almost one-third of the patients [7].

Here we present clinical and molecular characterization of a new case of de novo complex small supernumerary marker chromosome (sSMC) consisting of the entire short arm of chromosome 18p associated with a centromere of either chromosome 13 or 21 , evidenced in a 5 -year-old boy during work up for moderate intellectual disability and dysmorphisms.

To the best of our knowledge, the scientific literature reports about 35 cases of pure trisomy 18 p, which may be originated by different chromosomal mechanisms: unbalanced translocations, duplications, deletion of $18 \mathrm{p}$ with an isochromosome 18p and supernumerary marker chromosomes, reviewed by Yu et al. [8].

To date, seven cases of isolated trisomy $18 p$ due to a sSMC have been reported, three of which have been characterized by array $\mathrm{CGH}$, in two of these the breakpoints and the size of the duplication are shown [9]. We reviewed similar cases reported in the DECIPHER database in order to identify patients carrying similar duplication [10]. We also considered smaller duplications within the region of interest, in order to evaluate the presence of critical regions implicated in the pathological phenotype.

Our case provides additional information about phenotypic effects of pure trisomy 18p, confirm chromosomal microarray analysis as goal standard to characterize complete sSMC, and supply additional elements for genetic counselling.

\section{Materials and methods}

DNA was obtained from whole blood with MagCore Extractor System H16 using MagCore Genomic DNA Large Volume Whole blood kit (RBC Bioscience). Concentration and purity of DNA was verified with NanoPhotometer P-Class. Array CGH was performed using
OGT (Oxford Gene Technologies) ISCA v2 $4 \times 180 \mathrm{~K}$ Microarray Kit according to the manufacturer's instructions. Patient's and the reference male DNA (Promega 147A) were labeled and hybridized using enzymatic labeling and hybridization protocols (OGT reagents). The image of the array was acquired using an Innoscan 710 Microarray scanner (Innopsis) and results were analyzed by Cytosure Interpret Software (v.4.8, Oxford Gene Technologies) using standard algorithms. FISH analysis was performed on lymphocyte metaphase spreads of the proband using specific chromosome 13/21 $\alpha$-satellite D13Z1/D21Z1 centromeric probes (Kreatech) and whole chromosome painting probes specific for chromosome 18 (Kreatech) according to manufacturer's recommendation.

\section{Case presentation}

The patient was initially referred to a child neuropsychiatry unit at the age of 5 for mild global development delay, especially in the speech area. He is the youngest of three males of healthy non-consanguineous Caucasians parents, (the mother was 35 years old, the father 42 at conception). He was born at 39.2 weeks of spontaneous and unremarkable pregnancy, birth weight was 3410 gr (25-50th percentile), length $51 \mathrm{~cm}$ (50-75th percentile), HC $34 \mathrm{~cm}$ (25-50th percentile). At delivery monolateral club foot was evident and corrected with plaster casts worn for 3 months. At birth he was normal. During instrumental work-up brain MRI was performed and the presence of type 1 Arnold Chiari malformation without hydrocephalus, syringomyelia or fibrolipoma of the terminal filum was evidenced. Gastroenterological evaluation was also performed for frequent episodes of vomiting, concomitantly with upper respiratory tract infections. At X-ray analysis during transit neither gastroesophageal reflux nor vomiting episodes were reported.

At the last follow-up at the age of 7 physical examination indicated a height of $117,8 \mathrm{~cm}$, weight of $25 \mathrm{~kg}$ and head circumference of $51 \mathrm{~cm} \mathrm{(25-50th} \mathrm{percentile} \mathrm{for} \mathrm{all}$ values) while neurological examination evidenced slight reduction in muscle tone in all districts and embarrassment of fine and global motor performance. Cognitive assessment performed by WISC IV scale indicated total IQ of $44(\mathrm{VCI}=48, \mathrm{PRI}=67, \mathrm{WMI}=61, \mathrm{PSI}=56$, $\mathrm{GAI}=52, \mathrm{CPI}=48$ ).

The boy has a regular feeding but he is still followed by clinicians of the gastroenterology unit, his sleep-wake rhythm is regular, has completed the second class of the primary school with personal support teacher, he willingly goes to school, relationship with other children and involvement in daily activities are good. 


\section{Results}

Chromosome analysis was performed from cultured peripheral blood lymphocytes using high resolution QFQ banding (550 bands) [11]. The patient showed an abnormal male karyotype: $47, \mathrm{XY}+$ mar, with a satellite $\mathrm{SSMC}$ in all the 50 metaphases analyzed (Fig. 1). Peripheral blood karyotype analysis performed on both propositus' parents was 46,XX for the mother and 46,XY for the father, in all the 100 metaphases analyzed, indicating that sSMC occurred de novo.

Array CGH was performed using the Oxford Gene Technology $4 \times 180 \mathrm{~K}$ platform revealed a duplication of the short arm of chromosome 18 spanning about $14,1 \mathrm{Mb}$, from $14257 \mathrm{bp}$ (18p11.32) to $14122546 \mathrm{bp}$ (18p11.21) (Fig. 2). It compasses 123 genes, including 64 protein coding genes. Interestingly a number of them is highly express in cerebral cortex (Fig. 3).
FISH analysis was performed on lymphocyte metaphase spreads of the propositus using specific chromosome 13/21 $\alpha$-satellite D13Z1/D21Z1 centromeric probes. The analysis showed the presence of five hybridization signals corresponding to two chromosome 13 centromeres, two chromosome 21 centromeres and the centromere of sSMC (Fig. 4). In addition, the sSMC was partially hybridized by the whole chromosome 18 painting probes (Fig. 5). The final karyotype according to International System for Human Cytogenetic Nomenclature (ISCN 2016) is:

$$
47, \mathrm{XY},+ \text { mar dn.ish } \operatorname{der}(13 \text { or } 21) \mathrm{t}(13 \text { or }
$$
21;18)(q11;p11.21)(D13Z1/D21Z1+,wcp18+). arr[GRCh37]18p11.32 p11.21(14257_14122546)x3

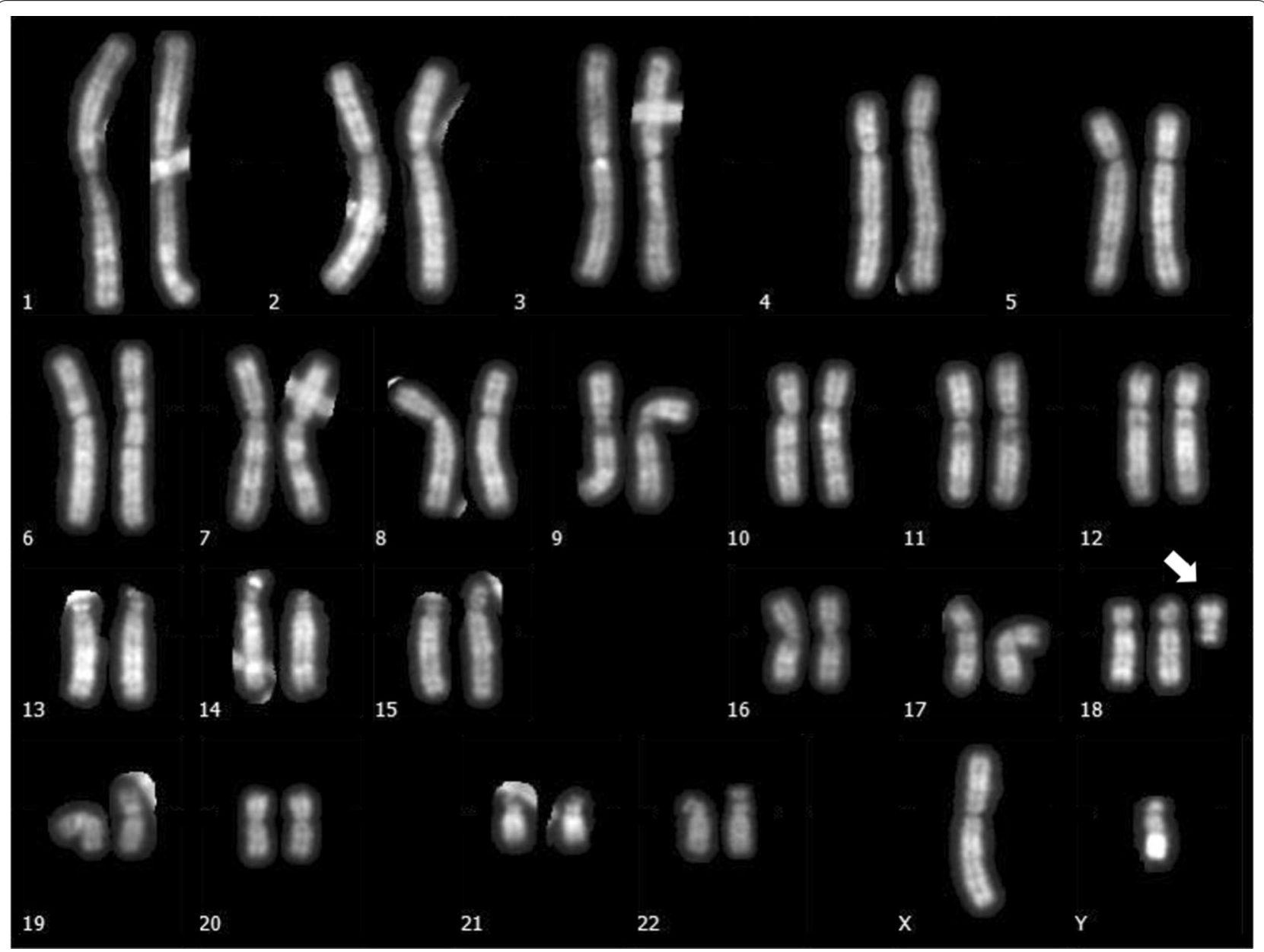

Fig. 1 Metaphase of peripheral blood of the proband showing the presence of a supernumerary marker chromosome (white arrow). Cytogenetic analysis was performed using Q-banding at 550 bands resolution, in line with the International System for Human Cytogenetic Nomenclature (ISCN 2016) 



Fig. 2 Array-CGH analysis: ideogram of chromosome 18 and dot plot of the duplication in 18p11.32p11.21, highlighted in the pink box (upper panel). Detail of the duplicated region spanning about $14 \mathrm{Mb}$ as shown in the UCSC Genome Browser (lower panel). A number of piRNA genes present in the region has been omitted. The chr18:14,257-14,122,546 coordinates are relative to the GRCh37/hg19 assembly

\section{Discussion and conclusion}

Trisomy $18 \mathrm{p}$ is a rare chromosomal aberration usually not associated to a characteristic facial appearance with a cognitive spectrum ranging from normal intelligence to moderated intellectual disability. To the best of our knowledge there are six cases with pure 18 trisomy associated to sSMC. (Resumed in Table 1). Five of these consist of the entire short arm of chromosome 18 translocated to a chromosome $13 / 21$ centromere $[9,12$, 13]: three are de novo while the other two are familial. Sheth et al., [14] describe another sSMC derived from $18 \mathrm{p}$ but data on the origin of the centromere is missing. 


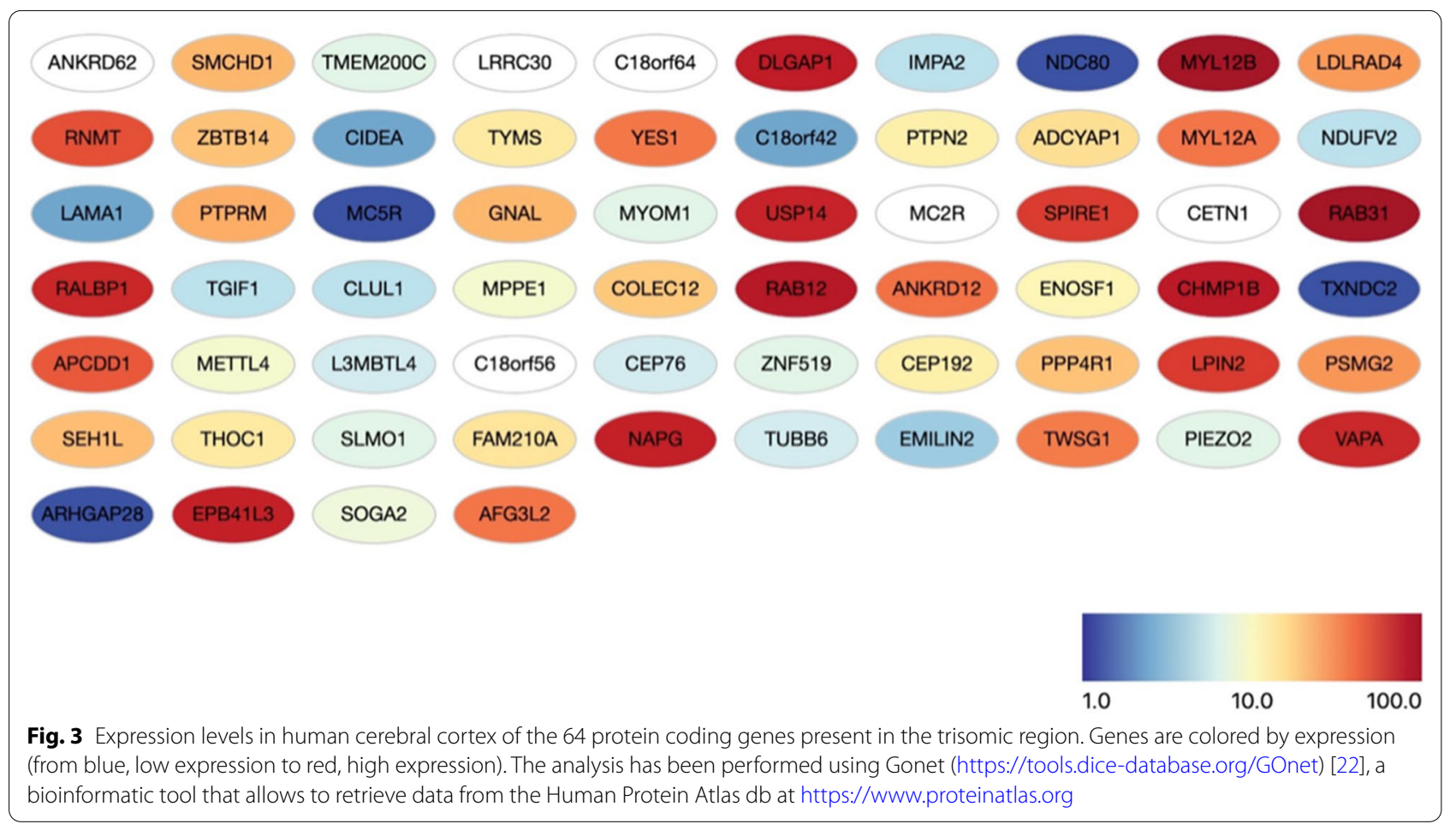

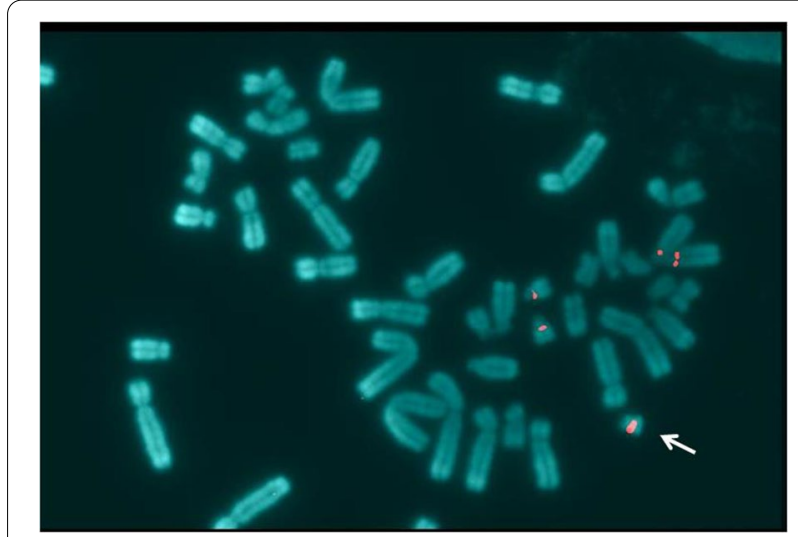

Fig. 4 FISH analysis performed with D13Z1/D21Z1 centromeric probes (Kreatech ${ }^{\mathrm{TM}}$ ) which hibrydize both chromosomes 13 and chromosomes 21 centromeres. The image shows positive signals (labeled in red) on 13 and 21 omologues and an additional signal on SSMC (white arrow)

We describe a boy with a de novo trisomy of the entire short arm of chromosome 18 due to a sSMC originated from a complex rearrangement involving chromosome 18 and 13/21 centromeres. He shows moderate intellectual disability congruently with previously reported case with similar chromosome anomaly $[9,12,13]$. The trisomic region includes 64 protein coding genes and it



is reasonable to hypothesize that the over-expression of some of them is responsible for the phenotypic abnormalities observed in the proband. Interestingly a number of them are highly expressed in cerebral cortex, indicating a significant biological role in CNS (Fig. 3). 11 of the genes present in triple copy are mutated in genetic disorders according to the OMIM database. 


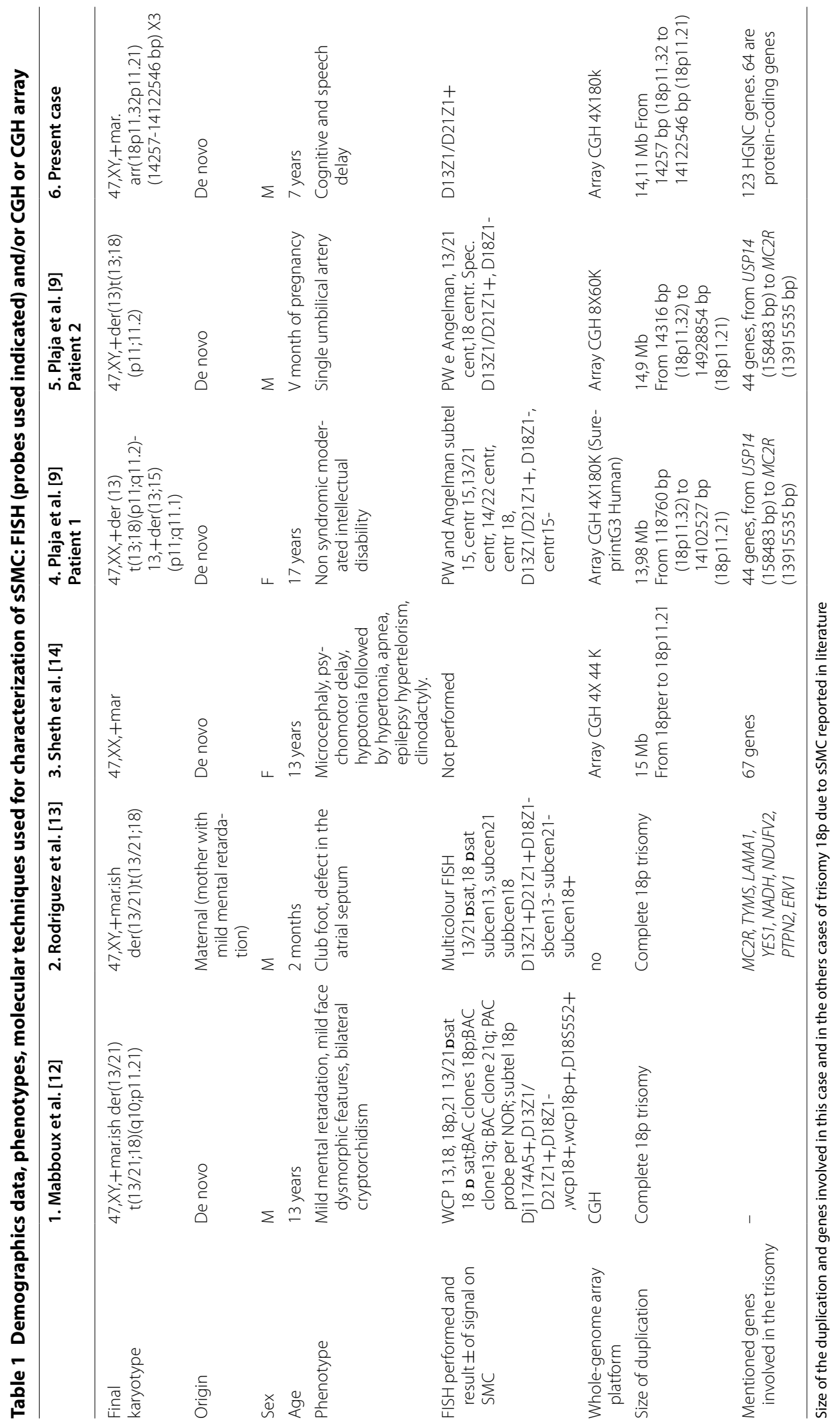


Plaja et al. [9] have described two cases of sSMC derived from 18p with 13/21 centromeres: the first found in a 17 years old girl with non-syndromic intellectual disability and the second found during prenatal investigations in a 36 years old woman who underwent to amniocentesis for advanced maternal age. In the last case pregnancy was interrupted in consideration of fetal karyotype. Both patients show duplications of almost entire short arm of chromosome 18 spanning 13,98 $\mathrm{Mb}$ and $14,9 \mathrm{Mb}$ respectively with breakpoints located within the $2 \mathrm{Mb}$ pericentromeric region of $18 \mathrm{p}$. In a previous study reporting the same anomaly only FISH and/or CGH analysis were performed $[12,13]$ and the size of duplication is missing. Our case shows a duplication of almost entire short arm of chromosome 18 spanning 14,1 Mb with a 1,3 $\mathrm{Mb}$ pericentromeric region showing a normal diploid state. On the basis of previously mentioned studies on similar cases we also performed 13/21 $\alpha$-satellite FISH analysis that showed the presence of positive signal on the centromere of sSMC. FISH assay does not allow to distinguish between centromeres of chromosome 13/21 because the $\alpha$-satellite subfamilies from chromosomes 13 and 21 are almost identical in sequence [15]. The duplicated region present in the sSMC of our proband encompasses 123 genes, 64 of which are protein coding.

Analyzing the DECIPHER database (http://decipher. sanger.ac.uk) [10] we found 67 patients with a duplication in $18 \mathrm{p}$ as single variant: in these patients, whose age is not reported, 5 duplications are de novo, 22 are inherited and in the remaining 40 cases the inheritance is unknown. The size range goes from $60,35 \mathrm{~Kb}$ to $15,29 \mathrm{Mb}$, most duplications occur either in 18p11.32 or in p11.31 bands.

6 patients carry duplications of unknown origin slightly larger than ours ranging from 14,59 to $15,11 \mathrm{Mb}$ (vs $14,11 \mathrm{Mb})$ showing in addition to intellectual disability hypotonia and/or ataxia. These duplications encompass from a minimum of 14 to maximum of 20 of additional genes located on the centromeric side of the ZNF519 gene (see Fig. 2) however, among these genes only 2, $A N K D R 3 O B$ and POTEC, are coding protein involved in breast and ovarian cancer respectively $[16,17]$. Further studies will be needed to understand if and why these genes are involved in the more severe phenotype of the patients.

DECIPHER data seem to provide evidence about the role of small $18 \mathrm{p}$ duplications in worse clinical effects than the whole duplication. Beside intellectual disability, patients show other severe clinical features such as autism, abnormality of cardiovascular system morphology.

Deletions usually have serious effects while the interpretation of duplications is often a challenge and their role on the phenotype remain largely unresolved. If a gene at the ends of the duplication is broken, the phenotype of the subject could be comparable to haploinsufficiency. Moreover, a duplicated region could be inserted into another gene, but this does not happen in our subject.

In the literature there are some reports of interstitial microduplication that partially overlap each other with some genes in common. Giordano et al. [18] describe a microduplication of $320-431 \mathrm{~Kb}$ at $18 \mathrm{p} 11.31-\mathrm{p} 11.23$ identified through array $\mathrm{CGH}$ encompassing three genes (ARHGAP28, LINC00668 and LAMA1) in 10 years old boy with moderate psychomotor delay and other physical anomalies: cerebellar vermis hypoplasia, coloboma, deafness and GH deficiency.

DECIPHER patient ID 25404 carry a duplication of $1,11 \mathrm{Mb}$ at 18p11.31-p11.23 showing clinical features similar to those described by Giordano et al. [18]: aplasia/hypoplasia of cerebellar vermis, intellectual disability moderate sensorineural hearing impairment. The duplicated region compasses only five genes including $L A M A 1$, a gene mutated in Poretti-Boltshauser syndrome, a neurodevelopmental disorder presenting congenital cerebellar anomalies and characterized by delayed motor development with cognitive function ranging from normal to intellectually disabled [19]. It is tempting to speculate that $L A M A 1$ may be a dosage-sensitive gene, considering that both loss of function mutations and duplications result in cerebellar alterations.

Balasubramanian et al. [20] report a family where father and two daughters of 6 and 5 years carry the same duplication in 18p11.32-p11.31 characterized by array $\mathrm{CGH}$. This duplication is $2,6 \mathrm{Mb}$ in size and include 9 to $13 \mathrm{HGNC}$ genes. All patients show variable levels of intellectual disability, development delay and behavior difficulties without any physical anomalies variation except for microcephaly found in both siblings.

Kashevarova et al. [21] report on 8 years old boy with motor stereotypy, dysarthria, ADHD, autism and dysmorphic traits that carry a duplication of $350 \mathrm{~Kb}$ in 18 p11.32 region inherited from his apparently healthy father.

Why some subjects with specific genomic imbalance present intellectual disabilities and other abnormalities while in others the same imbalance is without clinical effect is not clear. Further study will be needed to understand also the role of environmental factors on phenotype.

The case here presented together with those previously reported supports the mild phenotype effect associated to the duplication of entire 18p. Extensive follow-up is essential to provide adequate genetic counseling when the same chromosomal anomaly is found in prenatal diagnosis. 


\section{Acknowledgements}

We are gratefull to the patient and his family for their partecipation in this study.

\section{Authors' contributions}

EM and FM prepared the manuscript. FM, TM, SM and FM performed genetic testing and analyzed the results, GB performed the genomic analysis. CP, EF, EF, EM provided medical care to the patient including genetic counselling. EM and GB revised the manuscript. All authors provided revisions and feedback on the manuscript draft. All authors read and approved the final manuscript.

\section{Funding}

This research received no specific grant from any funding agency.

\section{Ethics approval and consent to participate}

Informed consent for analysis and publication was obtained from parent's patients and the study protocol conforms to the Italian ethical guidelines.

\section{Author details}

${ }^{1}$ Laboratory of Cytogenetics and Molecular Genetics, Department of Molecular and Translational Medicine, University of Brescia, Brescia, Italy. ${ }^{2}$ Unit of Child Neurology and Psychiatry, Civil Hospital, Department of Clinical and Experimental Sciences, University of Brescia, Brescia, Italy. ${ }^{3}$ Division of Biology and Genetics, Department of Molecular and Translational Medicine, University of Brescia, Brescia, Italy. ${ }^{4}$ TOMA Advanced Biomedical Assay, Busto Arsizio, Varese, Italy.

Received: 12 August 2020 Accepted: 9 December 2020

Published online: 20 January 2021

\section{References}

1. Liehr T, Weise A. Frequency of small supernumerary marker chromosomes in prenatal, newborn, developmentally retarded and infertility diagnostics. Int J Mol Med. 2007;19(5):719-31.

2. Liehr T, Claussen U, Starke H. Small supernumerary marker chromosomes (sSMC) in humans. Cytogenet Genome Res. 2004;107(1-2):55-67.

3. Crolla JA, Youings SA, Ennis S, Jacobs PA. Supernumerary marker chromosomes in man: parental origin, mosaicism and maternal age revisited. Eur J Hum Genet. 2005;13(2):154-60.

4. Dennis NR, Veltman MW, Thompson R, Craig E, Bolton PF, Thomas NS. Clinical findings in 33 subjects with large supernumerary marker(15) chromosomes and 3 subjects with triplication of 15q11-q13. Am J Med Genet A. 2006;140(5):434-41.

5. Crolla JA. FISH and molecular studies of autosomal supernumerary marker chromosomes excluding those derived from chromosome 15: II. Review of the literature. Am J Med Genet. 1998;75(4):367-81.

6. Liehr T, Mrasek K, Weise A, Dufke A, Rodriguez L, Martinez Guardia N, et al. Small supernumerary marker chromosomes-progress towards a genotype-phenotype correlation. Cytogenet Genome Res. 2006;112(1-2):23-34.

7. Orendi K, Uhrig S, Mach M, Tschepper P, Speicher MR. Complete and pure trisomy $18 p$ due to a complex chromosomal rearrangement in a male adult with mild intellectual disability. Am J Med Genet A. 2013;161A(7):1806-12.

8. Yu Y, Jiang Y, Hu X, Zhang H, Liu R, Wang R. Two-generation transmission of trisomy 18p: prenatal diagnosis in a woman with mild intellectual disability. Cytogenet Genome Res. 2019;157(4):220-6.

9. Plaja A, Lloveras E, Martinez-Bouzas C, Barrena B, Del Campo M, Fernandez $\mathrm{A}$, et al. Trisomy $18 p$ caused by a supernumerary marker with a chromosome 13/21 centromere: a possible recurrent chromosome aberration. Am J Med Genet A. 2013;161A(9):2363-8.

10. Firth HV, Richards SM, Bevan AP, Clayton S, Corpas M, Rajan D, et al. DEClPHER: Database of chromosomal imbalance and phenotype in humans using ensembl resources. Am J Hum Genet. 2009;84(4):524-33.

11. Magri C, Marchina E, Bertini V, Traversa M, Savio G, Pilotta A, et al. SNP array and FISH analysis of a proband with a 22q13.2- 22qter duplication shed light on the molecular origin of the rearrangement. BMC Med Genet. 2015;16:47.

12. Mabboux P, Brisset $S$, Aboura A, Pineau D, Koubi V, Joannidis S, et al. Pure and complete trisomy $18 p$ due to a supernumerary marker chromosome associated with moderate mental retardation. Am J Med Genet A. 2007;143A(7):727-33

13. Rodriguez L, Liehr T, Mrasek K, Mansilla E, Martinez-Fernandez ML, Garcia A, et al. Small supernumerary chromosome marker generating complete and pure trisomy $18 \mathrm{p}$, characterized by molecular cytogenetic techniques and review. Am J Med Genet A. 2007;143A(22):2727-32.

14. Sheth F, Andrieux J, Sheth J. Supernumerary marker chromosome in a child with microcephaly and mental retardation. Indian Pediatr. 2010;47(3):277-9.

15. Maratou K, Siddique Y, Kessling AM, Davies GE. Novel methodology for the detection of chromosome 21-specific alpha-satellite DNA sequences. Genomics. 1999:57(3):429-32.

16. Jager D, Stockert E, Gure AO, Scanlan MJ, Karbach J, Jager E, et al. Identification of a tissue-specific putative transcription factor in breast tissue by serological screening of a breast cancer library. Cancer Res. 2001;61(5):2055-61.

17. Bera TK, Zimonjic DB, Popescu NC, Sathyanarayana BK, Kumar V, Lee B, et al. POTE, a highly homologous gene family located on numerous chromosomes and expressed in prostate, ovary, testis, placenta, and prostate cancer. Proc Natl Acad Sci USA. 2002;99(26):16975-80.

18. Giordano M, Muratore V, Babu D, Meazza C, Bozzola M. A 18p11.23-p11.31 microduplication in a boy with psychomotor delay, cerebellar vermis hypoplasia, chorioretinal coloboma, deafness and GH deficiency. Mol Cytogenet. 2016;9:89

19. Aldinger KA, Mosca SJ, Tetreault M, Dempsey JC, Ishak GE, Hartley T, et al. Mutations in LAMA1 cause cerebellar dysplasia and cysts with and without retinal dystrophy. Am J Hum Genet. 2014:95(2):227-34.

20. Balasubramanian M, Sithambaram S, Smith K. Inherited duplication of the short arm of chromosome 18p11.32-p11.31 associated with developmental delay/intellectual disability. Clin Dysmorphol. 2016;25(1):19-22.

21. Kashevarova AA, Nazarenko LP, Skryabin NA, Salyukova OA, Chechetkina $\mathrm{NN}$, Tolmacheva EN, et al. Array CGH analysis of a cohort of Russian patients with intellectual disability. Gene. 2014;536(1):145-50.

22. Pomaznoy M, Ha B, Peters B. GOnet: a tool for interactive gene ontology analysis. BMC Bioinform. 2018;19(1):470.

\section{Publisher's Note}

Springer Nature remains neutral with regard to jurisdictional claims in published maps and institutional affiliations.

Ready to submit your research? Choose BMC and benefit from:

- fast, convenient online submission

- thorough peer review by experienced researchers in your field

- rapid publication on acceptance

- support for research data, including large and complex data types

- gold Open Access which fosters wider collaboration and increased citations

- maximum visibility for your research: over $100 \mathrm{M}$ website views per year

At BMC, research is always in progress.

Learn more biomedcentral.com/submissions 